\title{
In the cross hairs of controversy
}

\section{Nancy Baron reviews a handbook for scientists keen to influence policy.}

$\mathrm{I}$ $\mathrm{n}$ the world of science communication, academia has its own scarlet letter: A, for Advocacy. Many scientists shudder at the thought of being branded advocates. As a result, they can undermine the message of their research by caveating every assertion, or even avoiding interaction with the public - something I have encountered many times as a science-communication coach.

Lee Badgett is an academic who has fought with that tension and come out swinging. A professor of economics and policy, she is a veteran analyst and public intellectual with decades of experience in policy debates about equality for lesbian, gay, bisexual and transgender (LGBT) people. Her pithy Twitter profile describes her life's work as "Studying LGBT economic inequality to figure out how to end it." The Public Professor, her third book, is an exhortation to scientists to become "activist-scholars" like her.

Badgett intends to reverse-engineer advocate-academics to teach others how to galvanize policymakers, the media and the community to pay attention to their research. Her prescription for confronting injustice in areas from civil rights to climate change entails "injecting scholarship into important debates, taking advantage of good timing, being willing to handle disagreement" and connecting with the public, activists and policymakers.

Badgett breezes past reasons not to engage, averring that as for bad news about advocacy, “There really isn't any." As someone who entered the fray as a union organizer during her graduate degree, she draws on her own experience to offer strategies for researchers to inform legislative chambers, courtrooms, businesses and social movements.

She recommends three steps for maximum impact. First, examine the big picture, understand the debate and master the rules of the game, including determining your own role in a conversation. If an economist wants to recommend changes to the minimum wage, for example, understanding the institutions that regulate wage policy is essential. Identifying the decision-makers, as well as what they need and when, is crucial in working out how to make your research relevant and timely.

Second, build a network in the social spheres you hope to influence. Badgett advises using your existing network for e-mail introductions, or finding a hook to make a

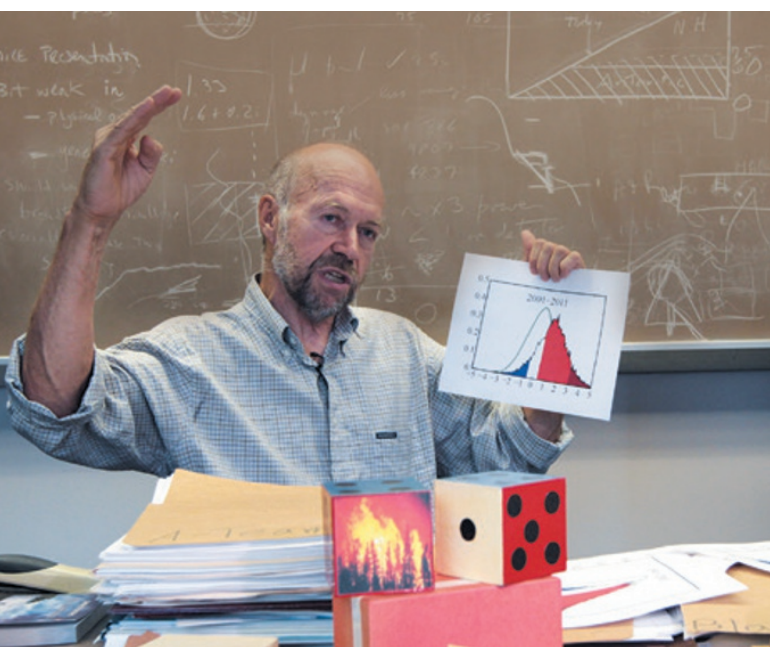

career-crushing backlash from going public. Badgett suggests addressing those concerns head on, and sooner rather than later. She does not fear the potential pitfalls, including obstacles to getting tenure, that can be a concern outside the social sciences. In ecology, for instance, public engagement can be viewed as a distraction from publishing - perhaps a different reaction from that in sociology or economics.

Badgett's tenure portfolio included a note from Barney Frank, long-time Massachusetts congressional representative, thanking her for sending him an article that he entered into the Congressional Record. She recommends building a network of academics who can vouch for your contributions to public debates and

cold call. A lawmaker who has introduced legislation may be keen to hear about how your research is relevant to it.

Third, practise the art of communicating with people outside your sphere. Prepare an elevator speech: what would you say to a US Congress member if you were in a lift with them for 30 seconds? Legislators are notorious for their short attention spans. The key is to distil your insights in a way that highlights their importance to the targeted person.

The payback for all such efforts, Badgett rightly notes, is that they generate feedback and ideas that can inform future research questions and improve your teaching.

Badgett advises academics who work on hot-button issues such as gay marriage, minimum wage or climate change to learn to manage conflict by seeing what lies behind it. Often it is politics, not science. The cost of avoidance, she writes, "is allowing others to dictate the debate and public outcome". Nor, she says, is being in the thick of the argument as difficult as neophytes imagine. In an intriguing section, "Developing a Thicker Skin", she writes: "for some scholars who haven't yet dipped their toe into the sea of engagement, once you are all the way in, you'll get used to the temperature". The best defence against attacks is to live and work
The Public

Professor: How to

Use Your Research

to Change the

World

M. V. LEE BADGETT

New York University

Press: 2015. by basic, ethical principles, she advises.

Her discussion of "sustainable engagement" in the long term may prove especially helpful to those with fears of a convince a tenure committee that they are worthy of credit. I have seen this strategy work, but it is patchy and dependent on leadership within departments and institutions.

I enjoyed reading about Badgett's experience, and would have welcomed more on lessons she has learned in the cross hairs. Her book skates over the surface of a large pond and sometimes feels on thin ice, with too few in-depth examples. Nor does it reference what I consider core reading, such as Cornelia Dean's Am I Making Myself Clear? (Harvard Univ. Press, 2012), an elegant book on the fundamentals of talking to journalists; Dennis Meredith's Explaining Research (Oxford Univ. Press, 2010), which is like having a topnotch public-information officer assigned to you; and Randy Olson's Houston, We Have a Narrative (Univ. Chicago Press, 2015; see Nature 526, 321;2015), an astute take on how to make science resonate through storytelling.

The Public Professor pushes the boundaries for scientists thinking of taking the public plunge. It will also be instructive to the more restrained scientist, as defined by Roger Pielke in The Honest Broker (Cambridge Univ. Press, 2007; A. A. Rosenburg Nature 448, 867; 2007). Researchers may feel that their fields are more constrained than the social-justice issues that Badgett champions, but The Public Professor has much to offer by exploring what is possible for those who want to change the world.

Nancy Baron is director of science outreach for communication-training service COMPASS and author of Escape from the Ivory Tower. e-mail:nbaron@compassonline.org 